\title{
Manejo da Caatinga para produção de caprinos e ovinos ${ }^{1}$
}

\author{
Management of the Caatinga for the production of goats and sheep
}

\author{
PEREIRA FILHO, José Morais²*; SILVA, Aderbal Marcos de Azevedo²; CÉZAR, \\ Marcílio Fontes ${ }^{2}$
}

\author{
${ }^{1}$ Revisão apresentada no Congresso Brasileiro de Zootecnia (ZOOTEC 2011). \\ 2Universidade Federal de Campina Grande, Unidade Acadêmica de Medicina Veterinária, Patos, \\ Paraíba, Brasil. \\ *Endereço para correspondência: jmorais@cstr.ufcg.edu.br
}

\section{RESUMO}

A maior parte da vegetação da Caatinga encontra-se em sucessão secundária com predominância de espécies invasoras e de baixo valor nutricional, das quais se destacam, entre as lenhosas, o marmeleiro e a jurema-preta. As plantas herbáceas, as folhas e ramos das espécies lenhosas produzem cerca de $4.000 \mathrm{~kg}$ de matéria seca/hectare/ano, mas apenas $10 \%$ (400kg) fica disponível ao pastejo dos animais, mesmo assim, as plantas forrageiras da caatinga são os componente principais da dieta de caprinos e ovinos da região. Esse aspecto, associado ao superpastejo, tem contribuído para o aumento de plantas de pouco valor nutricional, em substituição daquelas de melhor qualidade, o que pode resultar no desaparecimento de plantas forrageiras e acelerar uma possível degradação qualitativa da pastagem. Tal possibilidade tem preocupado técnicos e pesquisadores e os tem levado a buscar de alternativas de manejo da caatinga, com vistas a potencializar qualitativo e quantitativamente esses recursos forrageiros da Caatinga para a produção de caprinos e ovinos. Dentre as alternativas de manejo, destacam-se o rebaixamento, raleamento, enriquecimento, sistemas de podas, corte e conservação do excedente forrageiro da época chuvosa para utilização no período de estiagem, utilização de suplementação em pastejo, dentre outras. Assim, objetivou-se com esse trabalho apresentar e discutir alternativas de utilização dos recursos forrageiro da Caatinga na alimentação de pequenos ruminantes e sempre na perspectiva de uso sustentável da caatinga.

Palavras-chave: disponibilidade de forragem, feno, pastagem nativa, pastejo alternado.

\section{SUMMARY}

Most of the vegetation species of the Caatinga are in the process of secondary succession with predominance of invasive species with low nutritional value, such as the marmeleiro (Croton sonderianus Muell. Arg) and juremapreta (Mimosa tenuiflora (Willd.) Poir.), among the lignified species. The herbaceous species and the leaves and branches of lignified species generate around $4,000 \mathrm{~kg}$ of dry matter/ha/year, but only $10 \%(400 \mathrm{~kg})$ is available for animal grazing. All the same, forage plants of the Caatinga are the main components of the diet of goats and sheep in the region. This aspect associated to overgrazing has contributed to the increased number of low nutritional plants, which may lead to the disappearance of forage plants and accelerate the degradation of pasture quality. Therefore, the referred aspect has become very much a matter of concern of experts and researchers who seek alternative ways to manage the Caatinga regarding the production of goats and sheep. Some management alternatives include: thinning, enrichment, trimming, cutting and conservation of excess forage produced during the rainy seasons for use in the dry season, use of pasture supplementation, among others. Thus, the present study was aimed to present and discuss alternative uses of forage resources of the Caatinga in the feeding of small ruminants and from the perspective of a sustainable use of the Caatinga.

Keywords: alternative grazing, availability of forage, hay, native pasture. 


\section{INTRODUÇÃOO}

Historicamente, a Caatinga tem sido ocupada a partir da exploração extrativista de seus recursos naturais, que nos últimos anos tem alcançado índices preocupantes, pois atingem os mais diferentes setores como a extração da madeira, a caça indiscriminada de animais silvestres, a extração de mel de abelha, a colheita de frutos nativos e de plantas consideradas medicinais, dentre outras. No entanto, o superpastejo dos ruminantes e a agricultura itinerante vêm sendo apontadas como os principais fatores de degradação dos ecossistemas da Caatinga. Todos esses aspectos são agravados com a ocorrência de sucessivas secas e, sobretudo, pela concentração de renda e a exclusão social, política e econômica que ainda predominam na região.

A maior parte da vegetação da Caatinga se encontra em sucessão secundária e, em sua maioria, em direção à degradação, porém Araújo Filho et al. (2002) afirmam que se tomadas as medidas adequadas referentes ao manejo pastoril, boa parte pode ser trabalhada de forma sustentável. Nesse caso particular, Pereira Filho et al. (2007a) afirmam que a criação racional de caprinos e ovinos é determinante para adequação das técnicas de manejo da vegetação da Caatinga e a correta utilização do seu potencial forrageiro garante, em última análise, a melhoria das condições de vida do homem do campo.

Ainda que se reconheçam as dificuldades para o manejo da Caatinga, com vista a produção de caprinos e ovinos, existem trabalhos que demonstram o potencial forrageiro das plantas lenhosas (BAKKE et al., 2007) e herbáceas (PEREIRA FILHO et al., 2007a), bem como a possibilidade do excedente forrageiro produzido na época das chuvas ser armazenado na forma de feno (PEREIRA FILHO et al., 2003) ou silagem (SILVA et al., 2004). Todos esses estudos não desconsideraram formas mais intensivas de exploração da Caatinga, como o enriquecimento com gramíneas (SILVA et al., 2011) associado ou não com suplementação (CARVALHO JÚNIOR et al., 2009). Portanto, objetivou-se apresentar e discutir resultados que apontem alternativas de exploração racional dos recursos forrageiro da Caatinga para sua utilização na alimentação de caprinos e ovinos.

\section{CARACTERIZAÇÃO DA CAATINGA}

Mesmo com a existência de vários estudos, parece consensual a falta de uma definição clara de "Caatinga", que seja oficialmente aceita e reconhecida pela maioria dos estudiosos do tema. Em estudo da flora e vegetação desta, Rodal \& Sampaio (2002) identificaram três características básicas: "a vegetação que cobre uma área grande e mais ou menos contínua, no Nordeste do Brasil, submetida a um clima semiárido, bordejada por áreas de clima mais úmido; a vegetação desta área, com plantas que apresentam características relacionadas à adaptação à deficiência hídrica (caducifolia, herbáceas anuais, suculência, acúleos e espinhos, predominância de arbustos e árvores de pequeno porte, cobertura descontínua de copas); a vegetação com algumas espécies endêmica a esta área semiárida e com espécies que ocorrem nestas áreas e em outras áreas secas mais distantes, mas não nas áreas circunvizinhas".

Essas três características, segundo Sampaio (2010), são explicitamente relativas à vegetação, mas 
especificamente para a região de clima semiárido do Nordeste, e se fossem unicamente consideradas, esse gesto poderia resultar na exclusão de áreas sem adaptação à deficiência hídrica, e por outro lado, o relaxamento destas consideraria a Caatinga como um domínio. Dessa forma, "Caatinga" seria um termo regional, o que levaria a uma sobreposição das áreas de caatinga e de semiárido. Na literatura, observam-se citações com diferentes dimensões para o semiárido nordestino, a saber: $855.000 \mathrm{~km}^{2}$ (BNB, 2005), $955.000 \mathrm{~km}^{2}$ (GIULLIETI et al., 2006), $970.000 \mathrm{~km}^{2}$ (BRASIL, 2006). Ao particularizá-la como parte integrante do semiárido, Lima (1981) a considerou como domínio e a delimitou em $835.000 \mathrm{~km}^{2}$ de extensão, contudo o Ministério do Meio Ambiente a considera um importante bioma do Brasil, abrangente apenas de $734.000 \mathrm{~km}^{2}$ (SILVA et al., 2004).

Independentemente da extensão do semiárido e de acordo com a classificação de Koppen, predominam três tipos de clima na região, por ora listados: o BShw - semiárido, com curta estação chuvosa no verão $\mathrm{e}$ precipitações concentradas nos meses de dezembro e janeiro; o BShw' semiárido, com curta estação chuvosa no verão-outono e maiores precipitações nos meses de março e abril e; o BShs' semiárido, com curta estação chuvosa no outono-inverno e precipitações concentradas nos meses de maio e junho.

A precipitação anual varia de $150 \mathrm{~mm}$ a $1300 \mathrm{~mm}$ e média de $700 \mathrm{~mm}$. A temperatura média está em torno de $28^{\circ} \mathrm{C}$, com mínima de 8 e máxima ao redor de $40^{\circ} \mathrm{C}$, e umidade relativa do ar em torno de 60\%. Os solos predominantes da região são classificados como latossolos, litólicos, podzólicos, brunos não cálcicos, areias quartzosas e os planossolos solódicos. Quimicamente, podem ser adequados, mas, normalmente apresentam restrições físicas, drenagem irregular, acidez e pouca vocação agrícola.

Araújo Filho \& Crispim (2002) destacam a identificação de 12 tipos de Caatingas, com os dois modelos gerais seguintes: a Caatinga arbustiva-arbórea, dominante nos sertões, e a Caatinga arbórea, característica das vertentes e pés-de-serras e dos aluviões. As atividades pastoris tendem a ocupar o tipo arbustivo-arbóreo, enquanto a agricultura ocupa áreas antes restritas à Caatinga do tipo arbóreo. Os autores ressaltam ainda a presença de cerca de 596 espécies arbóreas e arbustivas, das quais 180 endêmicas, número de espécies que tende a aumentar, sobremaneira, se considerado $\mathrm{o}$ estrato herbáceo. Por último, tais pesquisadores reafirmam o grande potencial forrageiro, madeireiro, frutífero, medicinal e faunístico da região. Pereira Filho \& Bakke (2010) destacam que a ação do homem tem conduzido a vegetação da caatinga a um processo de sucessão secundária e que na maioria dos levantamentos feito, dentre as espécies lenhosas, as pioneiras como marmeleiro (Croton sonderianus) e jurema-preta (Mimosa tenuiflora) são as mais frequentes, com destaque ainda para a presença de outras espécies como catingueira (Caesalpinia bracteosa), mororó (Bauhinia cheilantha), mofombo (Combretum leprosum), dentre outras. Os autores destacam ainda que no estrato herbáceo as espécies comuns são: as gramíneas milhãs (Brachiaria plantaginea e Panicum sp.), capim-rabo-de-raposa (Setária sp.) e capim-panasco (Aristida setifolia) e; as dicotiledôneas, matapasto (Senna obtusifolia) alfazemabrava (Hyptis suaveolens), malvabranca (Sida cordifolia), feijão-de-rola (Phaseolus patyróides L.), centrosema (Centrosema sp), erva-de-ovelha 
(Stylosanthes humilis), manda-pulão (Croton sp.), bredo (Amaranthus sp.), dentre outras. Diante dessas características, parece natural que todos os caminhos apontem em direção a pecuária como uma das alternativas de exploração sustentada da Caatinga.

\section{MANEJO PASTORIL DA CAATINGA: POTENCIALIDADES E UTILIZAÇÃO}

Santos et al. (2010), em revisão sobre o potencial de plantas forrageiras da Caatinga na alimentação de ruminantes, destacam a variabilidade nos resultados das avaliações qualitativas e quantitativas dos recursos forrageiros desta. Nesse sentido, é importante ressaltar aspectos como: o nível de manipulação da vegetação da caatinga (ARAÚJO FILHO et al., 2002); o hábito de pastejo dos ruminantes e a necessidade de avaliação a longo prazo (PEREIRA FILHO et al., 2007); a possibilidade de conservação da forragem da caatinga produzida nas chuvas (FERREIRA et al., 2009) na forma de silagem (SILVA, et al., 2004) e de feno (PEREIRA FILHO et al., 2003) como estratégia de suplementação com volumoso na época de estiagem. Outro aspecto importante é a possibilidade de terminação de caprinos (CARVALHO JUNIOR et al. (2009) e ovinos (DANTAS et al., 2008) em Caatinga raleada e submetidos a diferentes níveis de suplementação, o que pode trazer respostas positivas no consumo total de matéria seca.

Segundo Araújo Filho (1992), o potencial de produção de matéria seca (MS) da Caatinga atinge em média $4000 \mathrm{~kg} / \mathrm{ha} /$ ano. Essa produção é resultante do somatório da porção forrageira da parte aérea das plantas lenhosas (árvores e arbustos), das folhas e ramos das espécies herbáceas. É importante ressaltar que nem toda forragem produzida fica disponível para o animal, bem como ocorre grande variação dessa produção em função de fatores ambientais, tais como: a estação do ano e a ação antrópica, especialmente quanto à forma e à intensidade de uso dos recursos forrageiros. Normalmente, a maior disponibilidade de forragem ocorre na estação chuvosa e é fornecida pelo estrato herbáceo. À medida que se caracteriza o período de estiagem, as folhas senescentes das plantas lenhosas são incorporadas à dieta dos animais $\mathrm{e}$ podem representar o único recurso forrageiro disponível a estes em alguns tipos de Caatinga.

Por outro lado, a manutenção de bons índices de produção animal a partir da vegetação da Caatinga, sem comprometer a sua sustentabilidade, é o grande desafio. Os estudos de manipulação da Caatinga (ARAÚJO FILHO, 1992) destacam os seguintes níveis de manipulação da vegetação lenhosa (Tabela 1): rebaixamento, raleamento e enriquecimento.

O rebaixamento das plantas lenhosas da Caatinga corresponde ao que o homem do campo tradicionalmente conhece como broca, ou seja, corta todas as espécies lenhosas a uma altura de 30 a $40 \mathrm{~cm}$ do solo. A Caatinga deve ser rebaixada no terço final do período de estiagem e, dessa forma, tão logo se iniciem as chuvas, as plantas cortadas poderão utilizar suas reservas de carboidratos para rebrotarem, de modo a disponibilizarem forragem para os animais, além de proporcionar, especialmente nos locais com menos rebrotas, o desenvolvimento do estrato herbáceo. Assim, costuma-se dizer que o rebaixamento tem o objetivo claro de disponibilizar a produção de massa verde dos arbustos e árvores, a qual de outra maneira estaria indisponível para 
o ramoneio/pastejo, de forma a situá-la ao nível do alcance dos animais, principalmente dos caprinos.

O raleamento consiste no controle de plantas lenhosas indesejáveis, o que reduz o sombreamento do solo por estas, para patamares em torno de 30 a $40 \%$, de modo a permitir a penetração dos raios solares e, ao iniciarem as chuvas, as sementes das plantas herbáceas germinem e se desenvolvam satisfatoriamente. Dessa forma, o estrato herbáceo torna-se mais representativo na produção de forragem da caatinga e na maioria das vezes fica totalmente disponível aos animais. É uma espécie de corte seletivo, no qual as plantas invasoras e tóxicas aos animais são as primeiras a serem controladas. $\mathrm{Na}$ prática, costuma-se afirmar que o raleamento transfere a produção de biomassa dos arbustos e árvores para o estrato herbáceo. O mais importante é que essa técnica aumenta consideravelmente a matéria seca pastável, oriunda de gramíneas e dicotiledôneas herbáceas, o que a torna mais indicada para ovinos e bovinos.

Tabela 1. Produção de matéria seca nos diferentes níveis de manipulação da Caatinga

\begin{tabular}{|c|c|c|c|c|c|}
\hline \multirow{2}{*}{ Nível de manipulação } & \multirow{2}{*}{$\begin{array}{c}\text { Produção (kg } \\
\text { MS/ha/ano) }\end{array}$} & \multicolumn{2}{|c|}{ Distribuição da fitomassa } & \multirow{2}{*}{$\begin{array}{c}\text { Fitomassa } \\
\text { pastável (\%) }\end{array}$} & \multirow{2}{*}{$\begin{array}{c}\text { Cobertura } \\
\text { Lenhosa }(\%)\end{array}$} \\
\hline & & Lenhosa $(\%)$ & Herbácea $(\%)$ & & \\
\hline Caatinga nativa & 4000 & 90 & 10 & $10(400 \mathrm{~kg})$ & $30-100$ \\
\hline Caatinga rebaixada & 4000 & 60 & 40 & $40(1600 \mathrm{~kg})$ & $50-60$ \\
\hline Caatinga raleada & 4000 & 20 & 80 & $60(1600 \mathrm{~kg})$ & $30-40$ \\
\hline Caatinga enriquecida & 4000 & 10 & 90 & $90(3600 \mathrm{~kg})$ & $10-15$ \\
\hline
\end{tabular}

Fonte: Adaptado de: Araújo Filho \& Crispim (2002), Araújo Filho (1992).

O sucesso do raleamento e a manutenção de bons índices de disponibilidade de forragem herbácea exigem controle da rebrota das plantas lenhosas, que deverá ser realizado durante a estação chuvosa. Carvalho et al. (1998) avaliaram as flutuações dos níveis dos carboidratos de reserva nas raízes e no caule do marmeleiro (Croton sonderianus) $\mathrm{e}$ observaram que esta espécie apresenta curva de carboidratos em forma de "U", ou seja, se ocorrer cortes no período compreendido entre o intumescimento das gemas e a frutificação (80 a 100 dias) em que estas reservas são mantidas baixas a capacidade de recuperação das plantas é prejudicada, o que facilita assim o controle.

Para Carvalho et al. (2001), se a principal lenhosa a ser controlada for o marmeleiro, esta deve ter suas rebrotas cortadas quando atingirem 75 a $100 \mathrm{~cm}$ de comprimento. Com essa prática, os autores verificaram que uma densidade de 12048 marmeleiros/ha possibilitou apenas $527,6 \mathrm{~kg}$ de MS proveniente do estrato herbáceo, mas com o controle desta o número de plantas/ha foi reduzido para 600 e a disponibilidade de MS subiu para 3932,3kg/ha. Já em relação à jurema-preta, Pereira Filho \& Bakke (2010) recomendam cortar as rebrotas quando a maioria atingir sete milímetros de diâmetro. Com esse procedimento, os autores observaram que, em áreas com 1731 espécimes de jurema-preta/ha, a disponibilidade de matéria seca foi $847,7 \mathrm{~kg} / \mathrm{ha}$, e, após o raleamento e controle das rebrotas, a densidade de jurema foi reduzida para 500 a 600 plantas/ha, e a disponibilidade do estrato herbáceo aumentou para 
3098,6kg/ha. Pereira Filho et al. (2010) ao estudarem a altura de corte como forma de controle da jurema-preta, concluíram que esta pode ser controlada através do corte realizado no meio do período de estiagem (setembro), na altura de 75 e $100 \mathrm{~cm}$, com as rebrotas cortadas no período das chuvas, quando atingirem diâmetro de sete milímetros, mas o controle da jurema-preta com corte de uniformização, em dezembro, apresentou baixa eficiência, independentemente da altura de corte utilizada.

$\mathrm{O}$ enriquecimento da Caatinga consiste em fazer um raleamento mais intenso, de modo a deixar cerca de $15 \%$ do solo coberto por plantas lenhosas e, em seguida, se faz a introdução de espécies forrageiras exóticas e/ou nativas, com o objetivo de aumentar a produção e a disponibilidade de MS pastável, assim como, a melhoria na capacidade de suporte. A maioria dos trabalhos realizados com gramíneas na região semiárida indica que melhores resultados são obtidos quando da utilização das espécies Cenchrus ciliaris (CapimBuffel), Cynodon dactylon (CapimGramão), Andropogon gayanus (CapimAndropogon) e Urochloa mosambicensis
(Capim-Corrente). Em termos de enriquecimento da Caatinga com utilização de leguminosas, existem poucos trabalhos e as mais usadas são Leucaena leucocephala (Leucena), Critoria ternatea (Cunhã), Stylosanthes humilis (erva-de-ovelha) e Cajanus cajans (Feijão guadu).

A maioria dos trabalhos que avaliam a disponibilidade de matéria seca da vegetação da Caatinga destaca valores de 1500 a $4000 \mathrm{~kg} / \mathrm{ha}$ e que a depender das características de cada área, especialmente da cobertura do solo por plantas lenhosas, e da época de avaliação, a participação de gramíneas e dicotiledôneas herbáceas apresenta variações acentuada (Tabela 2). Além do efeito do pastejo de caprinos, Pereira Filho et al. (1997) destacam possíveis variações na composição florística da vegetação, quando ovinos passam a ocupar áreas anteriormente pastejadas por caprinos. Todos esses aspectos são corroborados no relatório técnico de Soares \& Pereira Filho (2009), produzido quando avaliaram a disponibilidade de matéria seca do estrato herbáceo em Caatinga raleada e enriquecida com capim buffel (Tabela 3 ).

Tabela 2. Disponibilidade de matéria seca do estrato herbáceo em Caatinga raleada e pastejado por caprinos

\begin{tabular}{|c|c|c|c|c|c|c|}
\hline \multirow{2}{*}{ Época do ano } & \multicolumn{3}{|c|}{ Disponibilidade de MS (kg/ha) } & \multicolumn{2}{|c|}{ Composição Florística (\%) } & \multirow{2}{*}{ Referência } \\
\hline & Gramíneas & Dicotiledôneas & Total & Gramíneas & Dicotiledôneas & \\
\hline Início (28/05/2007) & 1102,9 & 1759,5 & 2862,4 & 38,5 & 61,5 & \multirow{3}{*}{$\begin{array}{l}\text { Carvalho } \\
\text { Júnior et al. } \\
\text { (2009) }\end{array}$} \\
\hline Meio (09/07/2007) & 1417,9 & 1929,9 & 3347,8 & 42,4 & 57,6 & \\
\hline Final $(06 / 08 / 2007)$ & 1494,8 & 236,8 & 1731,6 & 88,6 & 11,4 & \\
\hline Início (01/06/1994) & 1677,2 & 525,9 & 2203,1 & 76,1 & 23,9 & \multirow{3}{*}{$\begin{array}{l}\text { Pereira Filho } \\
\text { et al. (2007a) }\end{array}$} \\
\hline Meio (01/09/1994) & 1271,6 & 409,5 & 1681,1 & 75,6 & 24,4 & \\
\hline Final (01/11/1994) & 1263,2 & 258,6 & 1521,8 & 83,0 & 17,0 & \\
\hline
\end{tabular}


Rev. Bras. Saúde Prod. Anim., Salvador, v.14, n.1, p.77-90 jan./mar., 2013 http://www.rbspa.ufba.br ISSN 15199940

Tabela 3. Disponibilidade de matéria seca e composição florística do estrato herbáceo de uma Caatinga raleada e enriquecida com capim-buffel no sertão da Paraíba em 2008

\begin{tabular}{|c|c|c|c|c|c|c|c|}
\hline \multirow[b]{2}{*}{ Época } & \multicolumn{4}{|c|}{ Disponibilidade de matéria seca $(\mathrm{kg} / \mathrm{ha})$} & \multicolumn{3}{|c|}{ Composição Florística (\%) } \\
\hline & $\begin{array}{l}\text { Capim } \\
\text { buffel }\end{array}$ & $\begin{array}{l}\text { Outras } \\
\text { Gram. }{ }^{1}\end{array}$ & Dic. $^{2}$ & Total & $\begin{array}{l}\text { Capim } \\
\text { buffel }\end{array}$ & $\begin{array}{l}\text { Outras } \\
\text { Gram. }{ }^{1}\end{array}$ & Dic. $^{2}$ \\
\hline \multicolumn{8}{|c|}{ Área pastejada por caprinos } \\
\hline Maio/2008 & 227,2 & 568,7 & 2349,9 & 3145,8 & 7,2 & 18,1 & 74,7 \\
\hline Junho/2008 & 437,4 & 143,7 & 2874,0 & 3455,1 & 12,7 & 4,2 & 83,1 \\
\hline Julho/2008 & 352,3 & 130,3 & 1690,4 & 2173,0 & 16,2 & 6,0 & 77,8 \\
\hline Setembro/2008 & 481,2 & 306,3 & 367,4 & 1154,9 & 41,7 & 26,5 & 31,8 \\
\hline \multicolumn{8}{|c|}{ Área pastejada por ovinos } \\
\hline Maio/2008 & 742,7 & 199,5 & 1536,1 & 2478,2 & 30,0 & 8,0 & 62,0 \\
\hline Junho/2008 & 971,6 & 122,8 & 1767,6 & 2862,1 & 33,9 & 4,3 & 61,8 \\
\hline Julho/2008 & 1039,9 & 606,4 & 1340,4 & 2986,7 & 34,8 & 20,3 & 44,9 \\
\hline Setembro/2008 & 868,6 & 274,5 & 780,6 & 1923,8 & 45,1 & 14,3 & 40,6 \\
\hline
\end{tabular}

${ }^{1}$ Gramíneas; ${ }^{2}$ Dicotiledôneas; Fonte: Soares e Pereira Filho (2009)

São poucos os estudos que avaliam a disponibilidade de matéria seca de arbustos e arvore da Caatinga e os trabalhos existentes não avaliam $o$ conjunto das plantas lenhosas e sim aquela espécie mais representativa. Bakke et al. (2010), ao avaliarem espécies arbóreo-arbustivas nativas da Caatinga na alimentação de pequenos ruminantes, afirmam que os ramos finos de Sabiá (Mimosa caesalpiniifolia), jurema-preta (Mimosa tenuiflora) e favela (Cnidoscolus phyllacanthus) podem contribuir significativamente na porção volumosa da dieta desses animais. Característica que possibilita manejá-las através de podas para produção de feno (BAKKE et al,. 2010). Fato observado por Bakke et al. (2007) que obtiveram uma produção de matéria seca de folhas e ramos (diâmetro $\leq 10 \mathrm{~mm}$ ), cuja variação foi de 2067 a $6467 \mathrm{~kg} / \mathrm{ha}$. Formiga et al. (2011) avaliaram a relação entre diâmetro do caule e a desidratação, composição química e produção do feno de juremapreta (Mimosa tenuiflora) concluíram que diâmetros inferiores a $6 \mathrm{~mm}$ permitem obter feno de melhor qualidade, mas se o objetivo for associar qualidade $\mathrm{e}$ quantidade da matéria seca, os galhos devem ser cortados com $6 \mathrm{~mm}$.

Normalmente, os trabalhos de composição química de plantas forrageiras da Caatinga são feitos com espécies lenhosas, avaliadas de forma individual, com destaque para as leguminosas (Tabela 4). Todavia, o estrato herbáceo é avaliado como um todo, porém Silva et al. (2010) e Carvalho Júnior et al. (2009) destacam a necessidade de separar e avaliar o estrato herbáceo em gramíneas e dicotiledôneas (Tabela 5).

Comumente, as dicotiledôneas apresentam teor de FDN inferior ao das gramíneas e de PB superior ao mínimo exigido (7\%) pelos microorganismos do rúmen. Ocorre o contrário com as gramíneas, cujo teor de $\mathrm{PB}$ pode comprometer a saúde dos animais à medida que se caracteriza o período de estiagem. Esse comportamento foi observado em áreas de Caatinga da Paraíba pastejada por caprinos (CARVALHO JÚNIOR et al., 2009) e por ovinos (RUFINO, 2005; SANTOS et al., 2010). 
Tabela 4. Matéria seca (MS), proteína bruta (PB), fibra em detergente neutro (FDN), fibra em detergente ácido (FDA) e tanino de algumas leguminosas avaliadas por diferentes autores

\begin{tabular}{|c|c|c|c|c|c|c|}
\hline \multirow{2}{*}{ Nome vulgar/científico } & \multirow{2}{*}{ MS (\%) } & \multicolumn{4}{|c|}{$\%$ na MS } & \multirow{2}{*}{ Referência } \\
\hline & & PB & FDN & FDA & Tanino & \\
\hline Catingueira (Caesalpinia bracteosa) ${ }^{* *}$ & 87,9 & 11,25 & 45,47 & 37,08 & 6,3 & Gonzaga Neto et al. (2001) \\
\hline Cipó-de-escada (Bauhinia guianenseis) ${ }^{*}$ & 48,7 & 21,1 & 64,7 & 43,1 & - & Zanine et al. (2005) \\
\hline Jurema-preta (Mimosa tenuiflora) $* *$ & 91,2 & 14,3 & 44,5 & 29,5 & 21,92 & Pereira Filho et al. (2007b) \\
\hline Mata-pasto (Senna obtusifolia) $* *$ & 90,9 & 7,6 & 66,7 & - & - & Barros et al. (1991) \\
\hline Mororó (Bauhinia cheilantha) ** & 90,1 & 19,0 & 40,3 & 20,8 & 12,73 & Beelen et al. (2002) \\
\hline Pau-rato ( Caesalpinia pyramidalis) * & 37,0 & 19,7 & 52,3 & 37,6 & - & Zanine et al. (2005) \\
\hline Sabiá (Mimosa caesalpinifolia) ** & 94,7 & 17,8 & 40,0 & 22,0 & 20,1 & Beelen et al. (2002) \\
\hline Vaqueta (Aspidosperma cuspa)* & 54,0 & 13,0 & 48,5 & 38,2 & - & Zanine et al. (2005) \\
\hline
\end{tabular}

*Material in natura; ** Feno

Tabela 5. Composição química das gramíneas e dicotiledôneas herbáceas de três áreas de Caatinga raleada no sertão da Paraíba

\begin{tabular}{|c|c|c|c|c|c|c|}
\hline Componente florístico & $\operatorname{MS}(\%)$ & $\mathrm{MM}^{1}$ & $\mathrm{~PB}^{1}$ & $\mathrm{~EB}^{2}$ & FDN & Época de coleta/ Fonte \\
\hline Gramíneas & 30,67 & 9,14 & 9,8 & 4,21 & 77,51 & \multirow{2}{*}{ Maio de 2007/Carvalho Júnior (2008) } \\
\hline Dicotiledôneas & 28,91 & 7,36 & 12,42 & 4,21 & 60,60 & \\
\hline Gramíneas & 51,75 & 6,15 & 4,35 & 4,14 & 79,64 & \multirow{2}{*}{ Junho de 2007/Carvalho Júnior (2008) } \\
\hline Dicotiledôneas & 71,48 & 5,98 & 8,29 & 4,27 & 66,35 & \\
\hline Gramíneas & 70,51 & 6,85 & 5,71 & 4,16 & 80,31 & \multirow{2}{*}{ Julho de 2007/Carvalho Júnior (2008) } \\
\hline Dicotiledôneas & 44,72 & 6,35 & 13,43 & 4,57 & 67,12 & \\
\hline Gramíneas & 43,26 & 7,68 & 6,84 & 4,52 & 66,53 & \multirow{2}{*}{ Maio de 2004/Rufino (2005) } \\
\hline Dicotiledôneas & 47,35 & 6,96 & 14,42 & 4,18 & 51,36 & \\
\hline Gramíneas & 66,54 & 7,30 & 4,08 & 4,48 & 79,27 & \multirow{2}{*}{ Setembro de 2005/Santos et al. (2010) } \\
\hline Dicotiledôneas & 50,63 & 6,70 & 9,22 & 4.42 & 68,31 & \\
\hline Gramíneas & 43,6 & 7,5 & 3,3 & & 83,8 & \multirow{2}{*}{ Julho de 2008/Silva et al 2010} \\
\hline Dicoyiledôneas & 25,6 & 8,0 & 8,7 & & 61,8 & \\
\hline Gramíneas & 76,9 & 6,4 & 1,4 & & 83,1 & \multirow{2}{*}{ Setembro de 2008/Silva et al 2010} \\
\hline Dicoyiledôneas & 77,1 & 4,5 & 4,1 & & 80,1 & \\
\hline
\end{tabular}

${ }^{\mathrm{l}}$ Dados expresso em percentagem da matéria seca; ${ }^{2}=\mathrm{Mcal} / \mathrm{kgMS}$ 
A composição botânica da vegetação da Caatinga pode ser alterada pelo pastejo dos animais, o que torna importante avaliar a participação das plantas na dieta e na vegetação. Araújo Filho et al. (1996) avaliaram a composição botânica e química da dieta de ovinos e caprinos, em pastagem nativa no sertão dos Inhamuns-CE, e observaram que, no início da estação seca, os ovinos preferiram mais gramíneas e menos espécies lenhosas do que os caprinos. Todavia, essa diferença desapareceu à medida que esse período se prolongou, o que levou a classificá-los como selecionadores intermediários de elevada flexibilidade alimentar em função da época e da disponibilidade de forragem. Por último, concluíram que a combinação dessas duas espécies aumenta a pressão de pastejo sobre as gramíneas.

Santos et al (2008), ao trabalharem com ovinos em pastejo na Caatinga, concluíram que o mês de coleta é o principal responsável pela variação na composição botânica da dieta e na proporção de folha, caule, fruto, semente e flores selecionada pelos ovinos. Silva et al. (1999), ao estudarem ovinos em pastejo de curta duração, verificaram que mesmo com elevados índices de produção, o pastejo contínuo e exclusivo por ovinos reduziu a presença das gramíneas, de modo a desestabilizar a composição florística do estrato herbáceo. A análise desses estudos sugere que o pastejo alternado de ovino e caprino possa contribuir na recomposição florística do estrato herbáceo da Caatinga.

Quanto à similaridade entre as dietas de caprinos e ovinos Araújo Filho et al. (1996) observaram que em termos de grupos de espécies vegetais, as maiores similaridades ocorreram na estação seca, isto é, 95,8\% para plantas lenhosas e 93,4\% para gramíneas, enquanto para dicotiledôneas herbáceas ocorreu na transição estações úmida/seca que foi de $75,9 \%$. Isso levou os autores a afirmarem que caprinos e ovinos apresentam elevado grau de aproveitamento da Caatinga.

Pereira Filho et al. (1997) observaram que no pico das chuvas dos anos de 1988 (início do pastejo de ovinos), 1992 (final do pastejo de ovinos e início do pastejo de caprinos) e 1994 (final do pastejo de caprinos) a frequência das dicotiledôneas aumentou e a das gramíneas de maior valor forrageiro como milha-roxa (Panicum spp) tenderam a cair com o pastejo dos ovinos, enquanto que as dos capins de pouco ou nenhum valor forrageiro como panasco (Aristida setifolia) cresceram. No período de pastejo dos caprinos, todas as gramíneas apresentaram aumento nas suas frequências com valores superiores ao do início do pastejo de ovinos; já as frequências das dicotiledôneas herbáceas permaneceram constantes. Tais resultados reforçam a afirmação de Baumont et al. (2000), de que em condições favoráveis, os ovinos exercem uma maior pressão de pastejo sobre as gramíneas de melhor valor nutricional. Para Heady (1975), esses resultados indicam perda na biodiversidade durante o pastejo dos ovinos e que o pastejo dos caprinos favoreceu a diversidade de espécies vegetais.

Quanto a um provável efeito do pisoteio animal sobre atributos do solo, Parente et al. (2010), no trabalho com caprino em área de caatinga e em avaliação de três taxas de lotação contínua e fixa de 3,1 caprinos/ha, 1,5 caprino/ha e 0,0 caprinos/ha, concluíram que a variação dos atributos físicos do solo nas áreas estudadas foi mais decorrente das características físicas do solo do que da ação do pastejo dos caprinos.

Dentre as alternativas de alimentação para caprinos e ovinos na época de estiagem, especialmente quando da 
ocorrência de sucessivos anos de seca, Silva et al. (2005) destacam as cactáceas nativas da Caatinga. Nesse sentido, Cavalcante \& Resende (2006) avaliaram o consumo de mandacaru (Cereus jamacaru P. DC.) por caprinos sem raça definida no semiárido da Bahia e observaram que os animais que permaneceram em pastejo na caatinga, das 7:30h às $12: 30 \mathrm{~h}$, e receberam suplementação de mandacaru das, $13: 30 \mathrm{~h}$ às $17: 30 \mathrm{~h}$, apresentaram ganho de $5,16 \%$ do peso vivo inicial, enquanto os animais que permaneceram na caatinga durante todo o dia perderam $5,25 \%$ do peso vivo inicial. Cavalcante \& Resende (2007) partiram da mesma metodologia, mas suplementaram com Xiquexique (Pilocereus gounellei (A. Weber ex K. Schum.) Bly. Ex Rowl) e verificaram que os caprinos que pastejaram a caatinga e foram suplementados apresentaram ganho de $4,93 \%$ do peso vivo inicial, enquanto os demais animais que apenas pastejaram perderam $6,23 \%$.

Moreira et al. (2008) submeteram caprinos sem padrão racial definido, na fase de crescimento, a três estratégias de suplementação com ração completa com $30 \%$ de volumoso (fenos de Maniçoba, Leucena, Gliricídia) e $70 \%$ de concentrado mais aleitamento materno e o tratamento "controle" - cabritos soltos na Caatinga acompanhados da mãe, durante o dia - e verificaram que o desempenho dos animais mantidos na Caatinga com as mães foi semelhante aos que foram suplementados com ração que continha gliricidia, mas ambos foram inferiores aos dos animais do grupo que recebeu ração com maniçoba e com leucena.

Uma alternativa para melhorar $\mathrm{O}$ desempenho de caprinos e ovinos, bem como as características de carcaça, é a suplementação em pastejo. Carvalho Júnior (2008) observou que caprinos F1
Boer $\mathrm{x}$ SRD terminados em caatinga raleada e suplementados com $1,0 \%$ do peso vivo em concentrado, aumentou o ganho de peso de 103 para $147 \mathrm{~g}$ diário, de modo a possibilitar a visualização de um efeito quadrático sobre o consumo de matéria orgânica com ponto máximo de $0,82 \%$ do PV em suplementação.

Andrade et al (2007) avaliaram a terminação de ovinos Santa Inês, em caatinga nativa, enriquecida com capimbuffel e suplementados com três níveis de concentrado e obtiveram ganho de peso vivo de 77,$0 ; 134,0$ e 190,0g/dia, para os níveis de suplementação $0,0,1,0$ e $1,5 \%$ de $\mathrm{PV}$, respectivamente. $\mathrm{O}$ bom desempenho de caprinos e ovinos tem sido associado não apenas à suplementação, mas a capacidade seletiva destes de incluírem na dieta espécies vegetais de elevado valor nutritivos.

Ainda que o trabalho focalize o manejo da Caatinga para produção de caprinos e ovinos, é necessário frisar que o uso pastoril da vegetação desta não deve ser tratado de forma isolada ou pontual, deve-se considerar, então, as atividades agrícola e silvícola. Portanto, o conhecimento do potencial pastoril da Caatinga e a sua utilização racional na alimentação animal ainda é um desafio e deve-se considerar aspectos como: que o superpastejo é determinante na degradação desta, mas deve-se reconhecer a existência de trabalhos técnico-científicos como rebaixamento, raleamento e enriquecimento que apontam para a melhor utilização dos recursos forrageiros da Caatinga; que os estudos devem levar em conta 0 comportamento alimentar de caprinos e ovinos, que se bem trabalhados permitem a estabilização da produção de gramíneas e dicotiledôneas herbáceas; que é importante reconhecer o valor nutricional das espécies vegetais da Catinga, mas considerar a existência de 
substâncias antinutricionais que podem trazer problemas aos animais; Por último, reiterar a necessidade de utilização dos recursos forrageiros herbáceos e lenhosos da Caatinga, tanto in natura como conservado na alimentação de ruminantes, especialmente de caprinos e ovinos.

\section{REFERÊNCIAS}

ANDRADE, I.S.; SOUZA, B.B; PEREIRA FILHO, J.M.; SILVA, A.M.A. Parâmetros fisiológicos e desempenho de ovinos Santa Inês submetidos a diferentes tipos de suplementação em pastejo. Ciência e Agrotecnologia, v.31, p.540-547, 2007.

LIMA, D.A. The caatingas dominium. Revista Brasileira de Botânica, v.4, p.149-163, 1981.

ARAÚJO FILHO, J.A.; GADELHA, J.A.; LEITE, E.R.; SOUZA, P.Z.; CRISPIM, S.M.A.; REGO, M.C. Composição botânica e química da dieta de ovinos e pastoreio combinado na região dos Inhamuns, Ceará. Revista Brasileira de Zootecnia, v.25, p.383395, 1996.

ARAÚJO FILHO, J.A. Manipulação da vegetação lenhosa da caatinga para fins pastoris. Sobral, CE: Embrapa-CNPC. 1992. 18p. (Circular Técnica).

ARAÚJO FILHO, J.A.; CARVALHO, F.C.; GARCIA, R.; SOUSA, R.A. Efeitos da manipulação da vegetaçãolenhosa sobre a produção e compartimentalização da fitomassa pastável de uma caatinga sucessional. Revista Brasileira de Zootecnia, v.31, n.1, p.11-19, 2002.
ARAÚJO FILHO, J.A.; CRISPIM, S.M.A. Pastoreio combinado de bovinos, caprinos e ovinos em áreas de caatinga no Nordeste do Brasil. In: CONFERÊNCIA VIRTUAL GLOBAL SOBRE PRODUÇÃO ORGÂNICA DE BOVINOS DE CORTE, 2002, Concordia, SC. Anais... Corumbá, MS: Embrapa pantanal, 2002. p.1-7.

BAKKE, I.A.; BAKKE, O.A.; ANDRADE, A.P.; SALCEDO, I.H. Forage yield and quality of a dense thorny and thornless "jurema preta" stand. Pesquisa Agropecuária Brasileira, v.42, n.3, p.341-347, 2007.

BAKKE, O.A; PEREIRA FILHO, J.M.; BAKKE, I.A.; CODÃO, M.A. Produção e utilização da forragem de espécies lenhosas da caatinga. In: GARIGLIO, M.A.; SAMPAIO, E.V.Sá B.; CESTARO, L.A.; KAGEYAMA, P.Y Uso sustentável e conservação dos recursos florestais da caatinga. Brasília: Serviço Florestal Brasileiro, 2010. p.160-179.

BANCO DO NORDESTE DO BRASIL - BNB. Proposta de dimensionamento do semi-árído brasileiro. Fortaleza, 2005. 108p.

BARROS, N.N.; FREIRE, L.C.L.; LOPES, E.A.; KAWAS, J.; JOHNSON, W. Estudo comparativo da digestibilidade de leguminosa nativa com caprinos e ovinos do "Sertão" cearense. Pesquisa Agropecuária Brasileira, v.26, n.8, p.1215-1218, 1991.

BAUMONT, R.; PRACHE, S.; MEURET, M.; MORAND-FEHRET, P. How forage characteristics influence behaviour and intake in small ruminants: a review. Livestock Production Science, v.64, p.15-28, 2000. 
BRASIL. Ministério da Integração Nacional. Nova delimitação do semiárido brasileiro. Brasília, 2006. 32p.

BEELEN, P.M.G.; BERCHIELLI, T.T.; BEELEN, R.; MEDEIRO, A.N. Influence of condensed tannins from Brazilian semi-arid legumes on ruminal degradability, microbial colonization and enzymatic activity. Small

Ruminant Research, v.61, p.35-44, 2006

CARVALHO JÚNIOR, A.M. Efeito da suplementação na terminação de Caprinos F1 (Boer x SRD) em pastagem nativa do Semi-Árido Paraibano. 2008. 79p.Dissertação (Mestrado) - Universidade Federal de Capina Grande, Patos.

CARVALHO JÚNIOR, A.M.; PEREIRA FILHO, J.M.; SILVA, R.M.; CÉZAR, M.F.; SILVA, A.M.A.; SILVA, A.L.N. Efeito da suplementação nas características de carcaça e dos componentes não-carcaça de caprinos F1 Boer x SRD terminados em pastagem nativa. Revista Brasileira de Zootecnia, v.38, n.7, p.1301-1308, 2009.

CARVALHO, F.C.; ARAÚJO FILHO, J.A.; REGO, M.C.; TELES, F.F.F.

Flutuações dos níveis dos carboidratos de reserva disponíveis nas raízes e no caule do marmeleiro (Cróton Sonderianus Mueli. Arg), ao longo dos diferentes estádios fenológicos. Revista Brasileira de Zootecnia, v.27, n.4, p.670-675, 1998.

CARVALHO, F.C.; ARAÚJO FILHO, J.A.; GARCIA, R.; ALBURQUERQUE, V.M. Efeito do corte da parte aérea na sobrevivência do marmeleiro (Croton sonderianus Muell.Arg.). Revista Brasileira de Zootecnia, v.30, p.930-934, 2001.
CAVALCANTE, N.B.; RESENDE, G.M. Consumo de xiquexique (Pilocereus gounellei (A. Weber ex K. Schum.) Bly. ex Rowl) por caprinos no semi-árido da Bahia. Revista Caatinga, v.20, n.1, p.22-27, 2007.

CAVALCANTE, N.B.; RESENDE, G.M. Consumo do mandacaru (cereus jamacaru p. dc.) por caprinos na época da seca no semi-árido de Pernambuco.

Revista Caatinga, v.19, n.4, p.402-408, 2006.

DANTAS, A.F.; PEREIRA FILHO, J.M.; SILVA, A.M.A.; SANTOS, E.M.; SOUSA, B.B.; CÉZAR, M.F.

Características de carcaça de ovinos Santa Inês terminados em pastejo e submetidos a diferentes níveis de suplementação. Ciência e

Agrotecnologia, v.32, n.4, p.12801286, 2008.

FERREIRA, A.L.; SILVA, A.F.; PEREIRA, L.G.R.; BRAGA, L.G.T.; MORAES, S.A.; ARAÚJO, G.G.L. Produção e valor nutritivo da parte aérea da mandioca, maniçoba e pornunça Revista Brasileira de Saúde e Produção Animal [online], v.10, n.1, p.129-136, 2009.

FORMIGA, L.D.A.; PEREIRA FILHO, J.M.; NASCIMENTO JÚNIOR; N.G.; SOBRAL, F.E.S.; BRITO, I.C.A. Diâmetro do caule, sobre a desidratação, composição química e produção de feno de jurema preta (Mimosa tenuiflora). Revista Brasileira de Saúde e Produção Animal [online], v.12, n.1, p.22-31, 2011.

GIULLIETI, A.M.; CONCEIÇÃO, A.; QUEIROZ, L.P. Diversidade e caracterização das fanerógamas do semi-árido brasileiro. Recife: Associação Plantas do Nordeste, 2006. 488p. 
GONZAGA NETO, S.; BATISTA, A.M.V.; CARVALHO, F.F.R.; MARTINEZ, R.L.V.; BARBOSA, J.E.A.S.; MELO, E.O.S. Composição química, consumo e digestibilidade in vivo de dietas com diferentes níveis de feno de catingueira (Caesalpinea bracteosa), fornecidas para ovinos Morada Nova. Revista Brasileira de Zootecnia, v.30, n.2, p.553-562, 2001.

HEADY, H.F. Rangeland

Management. New York: McGrawHill, 1975. 470p

MOREIRA, J.N.; VOLTOLINI, T.V.; MOURA NETO, J.B.; SANTOS, R.D.; FRANÇA, C.A.; ARAÚJO, G.G.L. Alternativas de volumosos para caprinos em crescimento. Revista Brasileira de Saúde e Produção Animal [online], v.9, n.3, p.407-415, 2008.

PARENTE, H.N.; SILVA, D.S.; ANDRADE, A.P.; SOUZA, E.S.; ARAÚJO, K.D.; MAIA, M.O. Impacto do pisoteio caprino sobre atributos do solo em área de caatinga. Revista Brasileira de Saúde e Produção Animal [online], v.11, n.2, p.331-341, 2010 .

PEREIRA FILHO, J.M.; ARAÚJO FILHO, J.A.; CARVALHO, F.C.; REGO, M.C. Disponibilidade de fitomassa do estrato herbáceo de uma Caatinga raleada submetida ao pastejo alternado ovino-caprino. Livestock Research for Rural Development. v.19, n.2, 2007. Disponível em: <http://www.lrrd.org/lrrd19/1/pere1900 2.htm>. Acesso em: 12 mar. 2011.

PEREIRA FILHO, J.M.; ARAÚJO FILHO, J.A.; REGO, M.C.; CARVALHO, F.C. Variações plurianuais da composição florística do estrato herbáceo de uma caatinga raleada, submetida ao pastejo alternado ovino-caprino. Revista Brasileira de Zootecnia, v.26, n.2, p.234-239, 1997.

PEREIRA FILHO, J.M.; BAKKE, O.A. Produção de Forragem de espécies herbáceas da caatinga. In: GARIGLIO, M.A.; SAMPAIO, E.V.Sá B.; CESTARO, L.A.; KAGEYAMA, P.Y Uso sustentável e conservação dos recursos florestais da caatinga. Brasília: Serviço Florestal Brasileiro, 2010. p.145-159.

PEREIRA FILHO, J.M.; VIEIRA, E.L.; KAMALAK, A.; SILVA, A.M.A.; CÉZAR, M.F.; BEELEN, P.M.G. Ruminal disappearance of Mimosa tenuiflora hay treated wich sodium hydroxide. Archivos de Zootecnia, v.56, n.216, p.959-962, 2007.

PEREIRA FILHO, J.M.; VIEIRA, E.L.; SILVA, A.M.A; CÉZAR, M.F. CARVALHO JÚNIOR, A.M. Efeito da altura de corte no controle da juremapreta [Mimosa tenuiflora (WILD) POIR.]. Revista Caatinga, v.23, n.2, p.51-58, 2010.

PEREIRA FILHO, J.M.; VIEIRA, E.L.; SILVA, A.M.A; CÉZAR, M.F.;

AMORIM, F.U. Efeito do tratamento com hidróxido de sódio sobre a fração fibrosa, digestibilidade e tanino do feno da jurema-preta (Mimosa tenuiflora. Wild). Revista Brasileira de Zootecnia, v.32, n.1, p.70-76, 2003.

RODAL, M.J.N.; SAMPAIO, E.V.S.B. A vegetação do bioma caatinga. In: SAMPAIO, E.V.S.B.; GIULIETTI, A.M.; VIRGÍNIO, J.; GAMARRAROJAS, C.F.L. (Eds.). Vegetação e flora da Caatinga. Recife: PNE/CNIP, 2002. p.11-24. 
RUFINO, S.R.M. Desempenho de cordeiros confinados e em pastejo submetidos a diferentes tipos de suplementação. 2005. 48p. Dissertação (Mestrado) - Universidade Federal de Campina Grande, Patos.

SAMPAIO, E.V.S.B. Caracterização do bioma caatinga. In: GARIGLIO, M.A.; SAMPAIO, E.V.Sá B.; CESTARO, L.A.; KAGEYAMA, P.Y Uso sustentável e conservação dos recursos florestais da caatinga. Brasília: Serviço Florestal Brasileiro, 2010. p.28-48.

SILVA, A.M.A.; SANTOS, E.M.; PEREIRA FILHO, J.M.; BAKKE, O.A.; GONZAGA NETO, S.; COSTA, R.G. Composição corporal e exigências nutricionais em proteína e energia para ganho de peso de cordeiros em região semi-árida. Revista Brasileira de Zootecnia, v.39, n.1, p.210-216, 2010.

SANTOS, G.R.A.S.; BATISTA, A.M.V.; GUIM, A.; SANTOS, M.V.F.; SILVA, M.J.A.; PEREIRA, V.L.A. Determinação da composição botânica da dieta de ovinos em pastejo na Caatinga. Revista Brasileira de Zootecnia, v.37, n.10, p.1876-1883, 2008.

SANTOS, M.V.F.; LIRA, M.A.; DUBEUX JÚNIOR, J.C.B.; GUIM, A.; MELLO, A.C.L.; CUNHA, M.V. Potential of Caatinga forage plants in ruminant feeding. Revista Brasileira de Zootecnia, v.39, p.204-215, 2010. (Supl. especial).

SILVA, J.G.M.; SILVA, D.S.; FERREIRA, M.A.; LIMA, G.F.C.; MELO, A.A.S.; DINIZ, M.C.N.M. Xiquexique (Pilosocereus gounellei (A. Weber ex K. Schum.) Bly. Ex Rowl.) em substituição à silagem de sorgo (Sorghum bicolor L. Moench) na alimentação de vacas leiteiras. Revista Brasileira de Zootecnia, v.34, n.4, p.1408-1417, 2005.

SILVA, J.M.C.; TABARELLI, M.; FONSECA, M.T.; LINS, L.V.

Biodiversidade da Caatinga: áreas e ações prioritárias para conservação. Brasília: Embrapa Semi-árido, 2004. 382p.

SILVA, M.M.C.; GUIM, A.; PMENTA FILHO, E.C.; DORNELLAS, G.V.; SOUSA, M.F.; FIGUEIREDO, M.V. Avaliação do padrão de fermentação de silagens elaboradas com espécies forrageiras do estrato herbáceo da caatinga Nordestina. Revista Brasileira de Zootecnia, v.33, n.1, p.87-96, 2004

SILVA, N.L.; ARAÚJO FILHO, J.A.; SOUSA, F.B.; ARAÚJO, M.R.A.

Pastoreio de curta duração com ovinos em caatinga raleada no Sertão Cearense. Pesquisa Agropecuária Brasileira, v.34, p.135-140, 1999.

SOARES, D.C.; PEREIRA FILHO, J.M. Relatório Final do PIBIC/CNPq/UFCG. Campina Grande: Universidade Federal de Campina Grande, 2009. 40p.

ZANINE, A.M.; SANTOS, E.M.; FERREIRA, D.J.; ALMEIDA, J.C.C.; MACEDO JÚNIOR, G.L.; OLIVEIRA, J.S. Composição bromatológica de leguminosas do semi-árido do Brasil. Livestock Research for Rural Development, v.17, n.8, 2005. Disponível em: <www.cipav.org.co/lrrd//rrd17/8/zani17 087.htm>. Acesso: 12 mar. 2011.

Data de recebimento: 10/11/2011 Data de aprovação: 16/05/2012 